\title{
Khung lý thuyết và mô hình nghiên cứu
}

\author{
Khúc Văn Quý
}

Ngày 25-12-2021

\begin{abstract}
Hôm nay đã là Noel, với người theo đạo Ki tô giáo ngày này còn quan trọng hơn cả Tết năm mới. Trong không khí Tết Noel, chén trà câu chuyện...và rồi xoay về chủ đề công việc hàng ngày 研究 [1].
\end{abstract}

Dùng hệ nguyên lý 3DMS (3D-Mindsponge-Serendipity) [2-6], tôi hào hứng khi đồng nghiệp đề cập đến hai thuật ngữ then chốt trong nghiên cứu: "khung lý thuyết" và "mô hình".

Sau một thời gian làm nghiên cứu tôi nhận ra để hiểu được hai thuật ngữ này cũng không dễ, đặc biệt với các em sinh viên mới làm nghiên cứu. Mà hiểu mới là một chuyện, còn áp dụng nó thuần thục lại là chuyện khác. Khi tôi về công tác tại trường Đại học Kinh tế, tôi bắt gặp các bạn gặp khó khăn trong việc triển khai một nghiên cứu khoa học, ví dụ, phải bắt đầu từ đâu và không biết phải làm thế nào để thực hiện một nghiên cứu trọn vẹn. Trong bài viết ngắn này tôi lần lượt trình bày và làm rõ hai thuật ngữ then chốt kể trên và hy vọng một số luận giải ngắn gọn sẽ có hữu ích nhất định cho các bạn.

\section{Nhận diện}

Khi làm một bản thảo khoa học, nhà khoa học trải qua nhiều công việc nhưng nôm na dễ hiểu dễ nhớ có thể chia thành 4 công việc chủ chốt: ý tưởng, dữ liệu, phương pháp, và việc viết. Đây cũng là những tiêu chí rõ ràng để đánh giá sự đóng góp của từng thành viên trong nhóm nghiên cứu và xem xét tư cách để chia sẻ quyền "đồng tác giả” cho công trình khoa học.

Trong từng phần kể trên, thì phần dễ và cũng là khó nhất chính là phần phương pháp.

Phần phương pháp dễ viết là bởi vì nó rõ ràng gắn với từng bước làm cụ thể để trả lời cho câu hỏi "làm như thế nào". Một công trình khoa học tốt tức là đảm bảo được yếu tố lặp lại (replication) của phần phương pháp. Để dễ hiểu, tôi vẫn thường ví phần phương pháp là công thức nấu ăn (cookbook) của người đầu bếp. Và công thức nấu ăn sẽ trả lời cho câu hỏi: để làm ra một món ăn cụ thể thì sẽ có bao nhiêu bước, từng bước làm gì, thực hiện như thế nào, cần bao nhiêu nguyên liệu, khi nào thì làm gì...

Phần phương pháp lại khó bởi có liên quan (có gắn) với phần khung khái niệm và mô hình. Mặc dù một số cho rằng khung khái niệm là phần tách riêng với phần phương pháp nhưng chúng ta nên hiểu nó là phần đứng trước mô hình trong phần phương pháp. Cố nhiên, đây là trái tim của bài nghiên cứu. Khi thẩm định chất lượng bản thảo, công việc đầu tiên của ban biên tập (người phản biện) thường là đánh giá phần phương pháp (một cách tổng thể) trong đó có khung lý thuyết (khái niệm) và mô hình nghiên cứu.

\section{Khung lý thuyết (khái niệm)}

Khung lý thuyết (khái niệm) là sự trình bày (các) lý thuyết (khái niệm) liên quan. Nhà khoa học có thể sử dụng nguyên vẹn lý thuyết của các tác giả khác, hoặc bổ sung/chỉnh sửa lý thuyết (khái niệm) đã có, hoặc đề xuất khung lý thuyết (khái niệm) mới hoàn toàn để sử dụng cho chủ 
đề nghiên cứu của mình. Cụ thể, khung lý thuyết (khái niệm) cho một nghiên cứu (cụ thể) thông thường trình bày rõ ràng về định nghĩa của từng thuật ngữ (khái niệm) chủ chốt và liên kết chúng lại để hình thành một hệ thống các khái niệm hoặc các yếu tố liên quan và giải thích rõ các mối quan hệ tương tác giữa các thành phần trong khung lý thuyết (khái niệm). Khung lý thuyết có một số đặc điểm (yêu cầu) như sau.

Thứ nhất, khung lý thuyết (khái niệm) có tính phù hợp với chủ đề nghiên cứu cụ thể. Chủ đề nào thì lý thuyết (khái niệm) ấy. Việc đi xây dựng khung lý thuyết (khái niệm) trước tiên dựa vào các "từ khóa" của chủ đề nghiên cứu để lần ra các khái niệm chủ chốt và các lý thuyết quan trọng liên quan.

Thứ hai, khung lý thuyết (khái niệm) có tính trừu tượng, khái quát cao. Do được tập hợp từ các khái niệm chủ chốt có liên quan với nhau nên khung lý thuyết có tính khái quát. Tính khái quát cao ở đây nghĩa là không đề cập đến những chỉ số, chỉ tiêu cụ thể nào.

Thứ ba, khung lý thuyết (khái niệm) có tính dẫn dắt cho mô hình nghiên cứu và có độ bao phủ (về nội dung) vừa phải, không quá rộng và quá hẹp. Vì nếu rộng quá hoặc hẹp quá thì sẽ khó khăn thậm chí không khả thi cho việc xây dựng mô hình nghiên cứu (thực nghiệm). Các bạn cần xem xét mô hình thực nghiệm (mô hình có biến cụ thể) khi xây dựng khung lý thuyết (mô hình trừu tượng chưa có biến cụ thể) và ngược lại, và để làm sao giữa chúng có sự ăn khớp, logic.

Các tạp chí tốt thường có yêu cầu cao về phần khung lý thuyết (khái niệm) vì thế trình bày đúng, đủ, đẹp phần khung lý thuyết (khái niệm) sẽ là điểm cộng để gia tăng cơ hội để bản thảo vượt qua vòng bình duyệt đầu tiên.

\section{Mô hình (thực nghiệm)}

Trong xu hướng khoa học gần đây, đặc biệt là trong lĩnh vực mà tôi đang làm là khoa học xã hội và nhân văn, môi trường, nghiên cứu định lượng đang trở nên phổ biến. Nghiên cứu định lượng ở đây chính được hiểu nôm na là nghiên cứu có sử dụng mô hình thực nghiệm (empirical model). Thông thường, khi sử dụng mô hình thực nghiệm, nhà khoa học muốn dùng kết quả từ mẫu nghiên cứu (sample) để khái quát hóa "kết quả nghiên cứu" cho quần thể (population). Khác với khung lý thuyết (khái niệm) khi đề cập đến lý thuyết (khái niệm) có tính "trừu tượng", mô hình chỉ đề cập mối quan hệ của các biến cụ thể (đo đếm được).

Có nhiều loại mô hình và mỗi loại lại có đặc điểm riêng. Ví dụ, một loại mô hình rất thông dụng là mô hình hồi quy được sử dụng để xác định mối quan hệ giữa biến (biến phụ thuộc và các biến độc lập). Xây dựng mô hình hồi quy thực chất là quá trình giải nghiệm cho phương trình toán để xác định mức độ tác động của các biến độc lập lên biến phụ thuộc hay là sự đóng góp của biến độc lập để giải thích sự biến thiên của biến phụ thuộc. Dựa vào kết quả ước tính của mô hình hồi quy, người ta biết được biến nào quan trọng, biến nào kém quan trọng. Đây cũng là lời giải cho câu hỏi nghiên cứu (giả thuyết nghiên cứu).

Mô hình quyết định đến số phận của công trình nghiên cứu và người ta đánh giá chất lượng mô hình nghiên cứu thông qua nhiều tiêu chí bao gồm sự phù hợp của loại mô hình, cách xây dựng mô hình, và dữ liệu...

Xây dựng mô hình vốn khó, ví dụ, lựa chọn biến không biết thế nào cho đủ, cho vừa nhưng phát hiện các khuyết tật của mô hình và xử lý các khuyết tật để có mô hình tốt còn khó hơn nhiều. Việc lựa chọn biến như thế nào tôi sẽ trình bày chi tiết ở một bài viết khác. 
Các bạn cũng thường bối rối trước sự đa dạng của mô hình. Hiện tại có nhiều loại mô hình đang được sử dụng trong lĩnh vực khoa học xã hội và nhân văn. Tùy từng chủ đề, mục tiêu mà người làm khoa học quyết định loại mô hình nào. Tuy vậy, người ta tạm chia ra hai loại trường phái nghiên cứu (mô hình nghiên cứu): Frequentist và Bayesian [7]. Khi theo trường phái nào, mô hình thực nghiệm nào thì người làm nghiên cứu sẽ dự kiến được các biến liên quan, đây cũng là cơ sở để xây dựng bảng hỏi.

Tóm lại, các bạn nên chú ý tập trung vào khung lý thuyết và mô hình ngay ở bước đầu tiên khi làm nghiên cứu vì đây là phần trụ cột của bài báo nghiên cứu. Tạp chí càng danh tiếng thì yêu cầu về phần khung lý thuyết (khái niệm) và mô hình càng cao, do đó các bạn cần dành thời gian để tìm hiểu và áp dụng cho thật thuần thục và đây là cách tốt nhất để bước vào con đường chinh phục khoa học chuyên nghiệp-đỉnh cao.

\section{Tài liệu tham khảo}

[1] Khuc, Q. Van. (2021). Questioning in the 3D-Mindsponge-Serendipity (3DMS) system. OSF Preprints. https://doi.org/10.31219/osf.io/uz2yn

[2] Napier, N. K., \& Vuong, Q. H. (2013). Serendipity as a strategic advantage?. In: Wilkinson (ed.) Strategic Management in the 21st Century (pp. 175-199). Praeger/ABC-Clio.

[3] Nguyen, M. H., Le, T. T., Nguyen, H. K. T., Ho, M. T., Thanh Nguyen, H. T., \& Vuong, Q. H. (2021). Alice in suicideland: Exploring the suicidal ideation mechanism through the sense of connectedness and help-seeking behaviors. International Journal of Environmental Research and Public Health, 18(7), 1-24. https://doi.org/10.3390/ijerph18073681

[4] Vuong, Q. H. (2021). Tìm hiểu về chữ nghiên cứu 研究. Nhovuonque. https://nhovuonque.blogspot.com/2021/12/tim-hieu-ve-chu-nghien-cuu.html

[5] Vuong, Q. H., \& Napier, N. K. (2014). Making creativity: the value of multiple filters in the innovation process. International Journal of Transitions and Innovation Systems, 3(4), 294. https://doi.org/10.1504/ijtis.2014.068306

[6] Vuong, Q. H., \& Napier, N. K. (2015). Acculturation and global mindsponge: An emerging market perspective. International Journal of Intercultural Relations, 49, 354367. https://doi.org/10.1016/j.ijintrel.2015.06.003

[7] Vuong, Q., La, V., Tran, T., Nguyen, M., \& Ho, M.-T. (2021). Bản hòa tấu dữ liệu xã hội. https://doi.org/10.31219/osf.io/9jreq 